\title{
Understandings of the component causes of harm from cigarette smoking in Australia.
}

\author{
Bill King $^{1}$, Ron Borland ${ }^{1}$, Hua-Hie Yong ${ }^{2}$, Coral Gartner ${ }^{3,4}$, David Hammond ${ }^{5}$, Stephan \\ Lewandowsky ${ }^{6,7}$ and Richard O'Connor ${ }^{8}$
}

${ }^{1}$ Cancer Council Victoria and School of Psychological Sciences, University of Melbourne, Melbourne, Australia

${ }^{2}$ School of Psychology, Deakin University, Melbourne, Austraila.

${ }^{3}$ Faculty of Medicine, School of Public Health, Herston University of Queensland, Brisbane, Australia

${ }^{4}$ Faculty of Health and Behavioural Sciences, University of Queensland and Queensland Alliance for Environmental Health Sciences, Brisbane, Queensland.

${ }^{5}$ School of Public Health and Health Systems, University of Waterloo, Waterloo, Canada.

${ }^{6}$ School of Psychology, University of Western Australia, Perth, Australia

${ }^{7}$ School of Experimental Psychology, University of Bristol, Bristol, UK.

${ }^{8}$ Department of Health Behavior, Roswell Park Comprehensive Cancer Center, Buffalo, USA

Bill King MSc, Research Fellow in Psychology, Ron Borland PhD, Professor of Psychology, Hua-Hie Yong PhD, Associate Professor, Coral Gartner PhD, Associate Professor and Theme Leader for Education and Professional Development, David Hammond PhD, Professor of Psychology, Stephan Lewandowsky PhD, Professor of Psychology, Richard O’Connor PhD, Professor of Oncology.

Corresponding author: Bill King, Cancer Council Victoria, 615 St Kilda Rd, Melbourne, Victoria, 3004. Bill.king@cancervic.org.au +61 395146281.

This is the author manuscript accepted for publication and has undergone full peer review but has not been through the copyediting, typesetting, pagination and proofreading process, which may lead to differences between this version and the Version of Record. Please cite this article as doi: 10.1111/dar.12995

This article is protected by copyright. All rights reserved. 


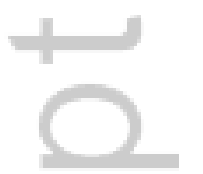

This article is protected by copyright. All rights reserved. 


\begin{abstract}
Introduction and Aims: To investigate relationships between smoking-related behaviours and knowledge of the disease risks of smoking and the causes of smoking harms, using a four-way division of "component causes": nicotine, other substances found in unburned tobacco, combustion products of tobacco and additives.
\end{abstract}

Design and Methods: The data were collected using an on-line survey in Australia with 1047 participants in three groups; young non-smokers (18 to 25), young smokers (18 to 25) and older smokers (26 and above).

Results: Most participants agreed that cancer and heart disease are major risks of smoking but only a quarter accurately quantified the mortality risk of lifetime daily smoking. Very few (2 of 1047) correctly estimated the relative contributions of all four component causes. Posthoc analyses reinterpreting responses as expressions of relative concern about combustion products and nicotine showed that $29 \%$ of participants rated combustion products above nicotine. We delineated six relative concern segments, most of which had distinctive patterns of beliefs and actions. However, higher levels of concern about combustion products were only weakly positively associated with harm reducing beliefs and actions.

Discussion and Conclusions: Most smokers do not appear to understand the risks of smoking and their causes well enough to be able to think systematically about the courses of action open to them to reduce their health risk. To facilitate informed decision-making, tobacco control communicators may need to better balance the dual aims of creating fear/negative affect about smoking and imparting knowledge about the health harms and their mechanisms.

Keywords: risk perception, harm reduction, nicotine, smoking 


\section{INTRODUCTION}

Smokers in countries with long histories of anti-smoking education generally know smoking is a major cause of lung cancer, heart disease and respiratory disease and substantially reduces life expectancy [1,2]. Around 95\% of smokers in Australia, Canada, the United Kingdom and United States agree that smoking is a major cause of lung cancer [3]. However, smokers know far less about the full range of health impacts. Most are unaware of quantitative estimates of the health-related harms of smoking [4] or do not believe such estimates apply to them personally [5].

Less is known about smokers' understanding of the mechanisms by which smoking causes disease. However, recent studies have found many smokers believe toxic chemicals are directly added to cigarettes, only a minority understand that most of the harm is due to tobacco combustion [6-10] and many overestimate the harmfulness of nicotine [11,12].

In this paper, we further investigate Australian adult smokers' understandings of the causes of harms from smoking and how this affects their thinking about related matters, including using other nicotine-containing products such as pharmaceutical nicotine replacement products (NRT) and nicotine vaping products (also called e-cigarettes). The research was guided by the Mental Models framework for risk perception [13-16]. Mental Models research is concerned with discovering what individuals currently know about a specific risk, and whether this knowledge is sufficiently integrated to inform practical decisions. (This level of integration is called "practical knowledge” in Bloom's typology of learning attainments, which traces learning from the simple ability to recall facts through increasingly systematic organisation of the knowledge held and increasing ability to apply that knowledge to solving practical problems [17]).

We delineated four main component causes of harm from smoking:

1. combustion products of tobacco, which are the main source of harm from smoking, contributing well over half of the risk $[18,19]$; 
2. toxic substances found in unburned tobacco that are transferred to smoke (these can vary markedly in concentration but contribute well under half of the risk of combustion products) [20,21];

3. additives (i.e. substances added to the tobacco by the manufacturers, including flavourings), which, in most cases, only constitute a small fraction of the weight of the tobacco rod (i.e. tobacco, plus additives), and their small direct contribution to harm is generally through combustion and formation of new compounds [19,22];

4. nicotine, which is a small direct contributor to the harms of smoking, although it plays a crucial indirect role in sustaining the behaviour over the years required for exposures to cumulate to produce the main health harms $[20,21,23,24]$.

Brewer and colleagues [6] employed a similar three-way division of component causes of harm from smoking, but did not distinguish nicotine from other substances occurring naturally in tobacco.

Lack of knowledge of the risks posed by these four component causes, particularly in terms of their relative magnitudes, could undermine smokers' efforts to protect their health. For example, overestimating the harm from nicotine may deter smokers from using NRT to quit smoking [25]. It might also prevent them from considering using an alternative form of nicotine delivery.

Our recent qualitative research [26] found poor understanding of the causes of harm from smoking. There was also a striking failure by some participants to use their general knowledge when they made harmfulness judgements about specific tobacco and nicotine products. They frequently used affect-based heuristics [27,28], including “quality”, “naturalness” and "liking” as markers of reduced harm, and "strength”, "harshness” and “dislike” as markers of increased harm. According to dual process theories [29,30], this may be because the knowledge was not sufficiently affectively salient to be accessed when the judgements were being made.

In this paper, we further investigate adult smokers' and non-smokers' general knowledge of the disease and mortality risks of smoking, and their ability to quantify the relative contributions of the four component causes described above. We had five main hypotheses: 
1) Only a minority of participants will be able to accurately estimate the relative contributions of the four component causes of harm; and

2) this more informed group will also have better knowledge of the harms of smoking.

Further, amongst current smokers and recent-ex-smokers,

3) those with accurate knowledge of the causes of harm will be more likely to have quit smoking , or if currently smoking, to have made recent quit attempts; and

4) will be more likely to be vaping; and

5) will hold more positive views about using non-combusted nicotine products.

\section{METHODS}

\section{Participants, recruitment procedure and rationale}

The survey was completed in March/April 2016, using a population representative Australian on-line panel with 176,255 members, and was conducted by the Social Research Centre, a subsidiary of the Australian National University (see www.srcentre.com.au for more details). Potential participants were informed the study was about smoking and quitting, was open to both smokers and non-smokers, and was being conducted by the Cancer Council Victoria. Those completing the survey were paid for their time.

The survey was conducted as part of a larger study exploring how beliefs about smoking-related harms affect practical choices, with a focus on beliefs affecting choices to vape. We focused on segments of the population most likely to change their smoking/vaping behaviours: current smokers (who might choose vaping as a harm reducing alternative), recent former smokers (who might choose vaping as a means to avoid relapsing ) and young non-smokers (who had never smoked but might vape in the future). We assumed that older non-smokers had a low likelihood of taking up either smoking or vaping and so concentrated available resources on recruiting from the aforementioned three groups. 
There were 34,492 invitations to participate and 4907 responses before recruitment ceased on day two (when the two quotas of more than 500 participants aged under 26 and more than 500 participants currently smoking, or who had recently quit had been exceeded). We received completed surveys for 1056 participants and included 1047 for analysis, after dropping two who did not confirm their smoking status, and respecifying the inclusion criteria for the two smoker groups to current smokers or ex-smokers who had quit within the previous 2 years (thus excluding any older vapers who had quit smoking more than two years ago). The final numbers were:

A. 337 younger non-smokers aged 18 to 25 (174 female, 163 male, mean age: 21.7, SD: 7.7). All self-reported that they had never smoked regularly.

B. 313 younger current smokers or recent quitters (<= 2 years), aged 18 to 25 (107 female, 206 male, mean age: 22.0, SD: 6.5).

C. 397 older current smokers or recent quitters (<=2 years) aged 26 and above (162 female, 235 male, mean age: 48.6, SD: 14.1).

\section{Measures}

Smoking and vaping status: Current smoking status was categorised as: (i) daily; (ii) less than daily; (iii) quit for less than 2 years; and (iv) never smoked/quit for more than 2 years. Vaping status was categorised as: (i) daily; (ii) less than daily; (iii) any past use; and (iv) never used (including “can’t say” responses).

Smoking status was determined by asking: "How often , if at all, do you CURRENTLY smoke cigarettes?,” with response options: “daily” and, “less than daily but more than weekly" plus "less than weekly" defining the two current use categories. Noncurrent smokers (who had answered 'not at all" to the previous question) were asked if they had ever smoked regularly, and those who had were asked: "When did you finally stop smoking?” with response options: within the last month, 1-3 months ago, 4-12 months ago, 12 years ago, combined to define recent quitters, with longer intervals only relevant for the non-smoker group. 
Vaping status was: (i) any current use; (ii) any past use; and (iii) never used (including those who reported "I have never heard of e-cigarettes").

Knowledge of smoking disease/mortality harms: We asked: “To what degree do you believe the following statements are true or false?": "Smoking is a major cause of cancer" and "Smoking is a major cause of heart disease." The response options for these two items were: 1 , definitely true; 2 , probably true; 3 , probably false; 4 , definitely false and 5 , can’t say. We accepted responses 1 and 2 as correct. We also asked: "What is a long-term smoker most likely to die of?” with response options: a disease caused by their smoking, a car accident, a disease caused by drinking too much alcohol, a disease caused by eating a poor diet, some other cause and can’t say. We also asked a quantitative question: "How many life-long smokers out of 100 will die prematurely from a smoking-related disease?” Participants were required to type in a number. We accepted answers of between 40 and 70 as correct, encompassing both current expert estimates of two in three and earlier estimates of one in two [31,32].

Knowledge of component causes of harm: We asked: "How much of the disease caused by cigarette smoking comes from the following?”: a, the nicotine in tobacco ; b, other harmful substances that occur naturally in tobacco; c, harmful substances that are produced when the tobacco burns; and d, substances that are added to cigarettes during the manufacturing process.” The response options were: (i) none or very little; (ii) some but less than half; (iii) around half; (iv) more than half; (v) all or nearly all of it; and (vi) can’t say. Responses accepted as correct were: 1 and 2 for both nicotine and additives, 2 and 3 for other harmful substances in tobacco, and 4 and 5 for combustion products. The item order was the same for all participants, as they appear in a logically dependent order.

Comparative ratings of products with respect to a reference cigarette: Using the most popular Australian cigarette (Winfield Blue) as the referent, participants rated perceived harmfulness of vaping products with and without nicotine, nicotine gum and nicotine mouthspray on a 0 to 10 scale ranging from "much less harmful" to "much more harmful" with the reference cigarette sitting on 5. There was also a “can’t say” option. 
Other measures: We asked: "How important to YOU are the following sources of information for making decisions about health related behaviours, such as smoking, diet and exercise and alcohol consumption?” We asked about eight information sources in the survey but only “information from medical researchers” was analysed here.

Revised measure of understanding (relative concern): Only a very small number of participants made accurate quantitative estimates of harm from the four component causes, which meant we could not test Hypotheses 2 to 4 in their original forms. Previous research by one of the authors demonstrated that responses to quantitative questions about risk or harm are sometimes made in relative terms reflecting concern (i.e. people are asked "how large is this particular risk?” but answer in terms of how concerned they feel about the particular risk. [4] Thus response of "all or nearly all” for a particular component cause would represent very high levels of concern about it, and "little or none” would represent very low levels of concern. We focused on the comparison between nicotine and combustion to generate the derived variable of relative concern, as this comparison was central to Hypothesis 4.

We divided the participants into six segments defined as follows: (i) combustion rated higher in risk than nicotine by two or more response categories (or “can’t say” to nicotine) (“clearly combustion”); (ii) combustion more concerning by one response category (“marginally combustion”); (iii) nicotine more concerning than combustion ("nicotine most”); (iv) the same rating of "more than half” or more for both ("over-concerned”); (v) the same rating of "around half” or below for both (“under-concerned”); and (vi) "can’t say” for both ("disengaged”). The final group is called disengaged, because anyone engaged with the issue would be expected to have a view and our working hypothesis was that this segment actively avoids thinking about the harms of smoking.

\section{Data analysis}

All analyses were conducted using Stata version 14. Young smokers (Group B) are used as the reference group for comparisons with the young non-smokers (A vs B) and older smokers (B vs C). Groups A and B differed on smoking status but shared age range, whereas Groups 
B and C differed on age but shared smoking status (allowing comparisons between younger and older smokers).

As the proportions of participants in the six segments did not differ significantly between the two smoker groups, they were analysed together for the post-hoc analyses. Because the disengaged segment accounted for many significant differences when all six segments were compared, we calculated $\chi^{2}$ measures for that segment versus the rest, along with comparisons amongst the other five segments (henceforth referred to as the "main five"). Where relevant, we also calculated $\chi^{2}$ measures for comparisons within the main five.

\section{Ethics approval}

The study was approved by the Cancer Council Victoria’s Low Risk Research Ethics Committee.

\section{RESULTS}

\section{Demographics, current smoking and vaping, and quit attempts}

Table 1 reports comparisons of the three participant groups in terms of gender and education. The non-smoker group had a higher proportion of females than the younger smoker group $\left(\chi^{2}(1)=20.1, P<0.001\right)$. The three participant groups did not differ significantly in educational attainment.

\section{INSERT TABLE 1}

Participants in the older smoker group were more likely than those in the younger smoker group to be daily smokers and were less likely to be currently not smoking at all $\left(\chi^{2}(3)=52.9, P<0.001\right)$. Participants in the older smoker group were also less likely than those in the younger smoker group to be currently vaping $\left(\chi^{2}(3)=29.5, P<0.001\right)$. Of 
participants who were currently vaping, those in the older smoker group were more likely to be vaping daily than those in the younger smoker group (45\% vs $29 \%, \chi^{2}(1)=5.21, P=0.02$, results not shown in Table 1).

\section{General knowledge of disease and mortality risks of smoking}

Most participants correctly identified smoking as a major cause of both cancer and heart disease and correctly identified smoking as the most likely cause of death for life-long smokers (Table 2). When those three items were considered together, younger non-smokers were significantly more likely than younger smokers to be correct for all three (adjusted odds ratio [AOR] 2.49 (1.73-3.58), $P<0.001)$, and younger smokers were significantly more likely than older smokers to be correct for all three (AOR 0.68 (0.50-0.93), $P=0.015)$. Both results became non-significant after adjusting for smoking and vaping experience.

\section{INSERT TABLE 2}

Around a quarter of all participants made estimates of the mortality risk of smoking within the broad range we defined as accurate (ie: 40-70\% die prematurely), with no significant differences between groups in terms of their likelihood of making accurate responses (AOR 1.16 (0.80 -1.68), $P=0.43$ and AOR 1.27 (0.90 - 1.80), $P=0.18$ ).

\section{Estimates of harm from the four component causes of harm from smoking}

Only two participants (both in the younger smoker group) responded to all four items within the accepted ranges. Our initial hypothesis was thus "over-confirmed.” This meant that hypotheses 2 to 4 were untestable in original form. Accordingly, we turned to exploring how this result might be explained and to developing alternative tests of our hypotheses.

Across the three participant groups, 43.5\% correctly responded that more than half of the disease caused by smoking is due to combustion. However, similar numbers responded with “more than half” or "all or nearly all” for tobacco itself (43.8\%) and additives (43.6\%), while

This article is protected by copyright. All rights reserved. 
somewhat fewer did so for nicotine (35.1\%). This is consistent with the questions being answered in terms of concern, rather than being strictestimates of proportions (which should add to one). We also found $48.2 \%$ responded with "more than half” or "all or nearly all” for two or more component causes and this rose to $62 \%$ when other patterns that clearly exceeded one were included (e.g., three or more responses of “about half”). The pairwise correlations for the four items were all positive, ranging from 0.25 to 0.68 (all $P<0.001$ ).

\section{Analyses using relative concern}

We tested Hypotheses 2 to 5 using the post-hoc measure of relative concern between combustion and nicotine, which was described in detail in the Methods, and we restricted these analyses to the two smoker groups.

The relative concern measure yielded a relatively even spread of participants across the six segments for the two smoker groups (as is shown in Table 3), and responses were generally similar between the two smoker groups, with younger smokers somewhat more likely to be in the overconcerned segment and somewhat less likely to be in the disengaged segment $\left(\chi^{2}(5)=10.8, P=0.06\right)$.

\section{INSERT TABLE 3}

\section{Relationships between relative concern and other measures}

Participants in the disengaged segment differed significantly from participants in the other segments on every comparison shown in Table 4. For the knowledge and attitude items, this was attributable to “can’t say” responses. Disengaged participants placed the least importance on information from medical experts $\left(\chi^{2}(2)=64.4, P<0.001\right)$, were more likely than participants in the main five segments to be exclusively smoking $\left(\chi^{2}(1)=21.1, P\right.$ $<0.001)$, less likely to be currently vaping $\left(\chi^{2}(1)=7.2, P=0.007\right)$ less likely to be currently

This article is protected by copyright. All rights reserved. 
quit $\left(\chi^{2}(1)=8.4, P=0.004\right)$, and the least likely to have made a quit attempt in the past year $\left(\chi^{2}(1)=20.6, P<0.001\right)$.

\section{INSERT TABLE 4}

Comparisons between the clearly combustion segment and the rest of the "main five" provide the best available means for testing the remaining hypotheses. Table 4 shows the results of comparisons amongst the main five segments. Participants in the clearly combustion segment did not differ significantly from those in the other four segments in terms of knowledge of harms and mortality risk, disconfirming Hypothesis 2. They were also not significantly more likely than the rest of the main five to be currently quit $\left(\chi^{2}(1)=1.44\right.$, NS), or, if currently smoking, to have made a quit attempt within the past year (see Table 4), disconfirming Hypothesis 3 . They were also no more likely to be currently vaping $\left(\chi^{2}(1)=\right.$ 0.40 , NS), disconfirming hypothesis 4 . However, they differed significantly in terms of correctly rating the two NRT products and two vaping products as less harmful than the reference cigarette $\left(\chi^{2}(1)=8.5, P=0.004 ; \chi^{2}(1)=8.6, P=0.003 ; \chi^{2}(1)=6.7, P=0.01\right.$; $\left.\chi^{2}(1)=5.4, P=0.02\right)$, providing support for Hypothesis 5. In additional analyses, they were also significantly more likely than those in the other four segments of the main five to rate information from medical experts as very or extremely important $\left(\chi^{2}(2)=14.0, P=0.001\right)$.

\section{Exploratory analyses of the other relative concern segments}

We theorised that the over-concerned segment would have high motivation to avoid both combustion products and nicotine, which should translate into high motivation to quit smoking but reluctance to use NRT or vape. By contrast, the under-concerned segment would be expected to have low motivation to change their smoking behaviours. We found participants in the over-concerned segment were more likely than the rest of the main five to agree smoking is a major cause of cancer and heart disease and is the main cause of premature death for life-long smokers $\left(\chi^{2}(1)=38.7, P<0.001\right)$. They were also more likely to 
be currently quit $\left(\chi^{2}(1)=10.4, P=0.001\right)$, although they did not differ significantly on vaping status. They were less likely to rate vaping with or without nicotine or using nicotine mouth spray as less harmful than smoking $\left(\chi^{2}(1)=8.1, P=0.004 ; \chi^{2}(1)=7.7, P=0.006 ; \chi^{2}(1)=5.1, P\right.$ $=0.02$ ), but did not differ from the rest of the "main five" in ratingsof nicotine gum.

Participants in the under-concerned segment were less likely than participants in the remainder of the main five agree that smoking is a major cause of cancer and heart disease and that it is the main cause of premature death for life-long smokers $\left(\chi^{2}(1)=13.5, P<0.001\right)$. They were less likely than the rest of the main five to be currently quit $\left(\chi^{2}(1)=8.2, P=0.004\right)$ but more likely to be currently vaping $\left(\chi^{2}(1)=14.4, P<0.001\right)$. They did not differ significantly from the rest of the main five in their ratings of the harmfulness of NRT and vaping.

Participants in the remaining two segments of the main five - marginally combustion and nicotine most - did not stand out on any belief or behaviour measures.

\section{DISCUSSION}

While much public discourse about smokers continues to assume that "they know the risks they are taking”, our results add to the research demonstrating otherwise. We found that Australian adult smokers have limited understanding of the risks they face from smoking, particularly when it comes to quantifying the risk. While most participants agreed that smoking is a major cause of cancer and heart disease, fewer recognised that smoking is the main cause of premature death in smokers. Fewer still accurately estimated the mortality. A quarter of the two smoker groups underestimated the lifetime mortality risk and this might be associated with lack of motivation to quit or switch to another form of nicotine delivery. A smaller proportion overestimated the risk. At first glance, that would scarcely be a problem for them. However, overestimating risks can undermine intention to change by producing "the damage has already been done" fatalism. 
By our original criterion, fewer than $1 \%$ of participants had adequate knowledge of the mechanisms by which smoking causes disease. While this may have been setting the bar too high, our results using relative concern confirmed most participants have limited knowledge and limited ability to apply it to practical decision making. Even participants in the clearly combustion segment did not perform particularly well on making some harmfulness judgements that follow from understanding that combustion is a much greater source of harm than nicotine. Only a bare majority in the clearly combustion segment responded that using nicotine mouth spray is less harmful than smoking and only a third of the segment responded that vaping with nicotine is less harmful than smoking. These results suggest that many smokers in the clearly combustion segment retain a strong implicit belief that nicotine is very harmful and that thinking about nicotine evokes negative affective associations. These results are broadly consistent with both recent US findings $[6,7,9,10]$ and findings from our earlier qualitative research [26].

The finding that participants in the under-concerned segment were the most likely to be vaping is intriguing. It does not fit with our expectation that participants in this segment would be content with continuing to smoke. However, it may fit with a more nuanced model of how affect influences thinking and decision making about risks. Appropriate affect is critical for making decisions and following through with appropriate action [30, 33]. Strong negative affect can produce intention to change behaviour, but the anxiety it can provoke also narrows thinking, constraining the search for solutions. .Insofar as they are less worried, participants in the under-concerned segment may have been more open to exploring alternative possibilities.Our findings are largely consistent with our previous explanation that the failure to use knowledge is in part a situation-based failure to access that knowledge when needed [26]. Further, even if this knowledge is used by them in their everyday lives, it may not generate sufficient affect to outweigh opposing affect generated when responding intuitively.

Our theoretical analysis points to the importance of encouraging the building of coherent conceptual models separately from situations in which strong evaluative feelings are experienced (which may include, say, viewing disturbing public health messages about 
smoking in the media or on cigarette packs). Developing concern before a coherent model is attained may interfere with the development of the model, and lead to reversion to experience-based heuristics, in which smokers first experience like or dislike of particular products then search for an explanation which will validate those likes and dislikes [26, 27]. This kind of decision making often leads to poor choices for managing health risks [26, 30]. Strengths and limitations of the study.

The current study was limited to Australia and it did not include older people who have never smoked, long-term ex-smokers or meaningful numbers of current vapers who have never smokedWe think it is unlikely that smokers from other countries would be much better informed than Australian smokers. Nonetheless, the study should be replicated with smokers from other countries.

Another limitation of the study was a lack of measures of potential associates of knowledge, including past and intended future use of NRT. This limits our understanding of the behavioural consequences of risk perceptions of nicotine in particular.

There are two major elements of a comprehensive mental model of smoking harms that we did not consider in the present study and which should be a focus of future work: exposure by inhalation into the lungs versus exposure by deposition in the buccal cavity and digestive tract; and dose-response relationships, including exposure duration and acute versus chronic exposure effects. Future research might also more explicitly focus on the strength of affective reactions to propositions about what is desirable and what should be avoided.

The present study also has significant strengths. By fortuitous discovery, following from our inability to test our original hypotheses, the study has opened up promising new ground for researching the interactions between the cognitive and affective drivers of behaviour change. Also, the survey content was grounded in interviews and focus groups, which identified themes that were important to smokers and ensured use of well-understood terms to describe the matters we were investigating. 


\section{Conclusions}

We found modest relationships between knowledge of the harms of smoking and their causes. We also found weak relationships between that knowledge and both beliefs about less harmful alternatives to smoking and actions. People are generally unable to make even rough quantitative estimates of harm, and even relative estimates appear unstable. If our theoretical analysis is correct, it points to the need for tobacco control programmes to focus more on helping smokers attain deeper knowledge (i.e. at the level of practical knowledge [17]). It is also harder to supress uncomfortable beliefs when we have detailed, emotionally charged reasons for considering them. We think there would be benefits if tobacco control messages made it clearer that combustion is the main cause of disease and avoided overstating the direct harms caused from other sources.

\section{Acknowledgements}

This study was supported by the Victorian Health Promotion Foundation (VicHealth) Tobacco Harm Reduction Programme (2014-0152) and by pilot research funding from the Hollings Cancer Center Support Grant (P30 CA138313) at the Medical University of South Carolina. We thank Jae Cooper, of Cancer Council Victoria, and Kylie Morphett, of University of Queensland, for suggestions about survey content, and Tina Petroulias and Sarah Studds, of the Social Research Centre, for advice on wording and ordering of survey items.

\section{Declaration of interests}

All of the authors declare that they have no competing interests.

This article is protected by copyright. All rights reserved. 
Table 1. Demographics, smoking and vaping in the three participant groups. All figures are expressed as percentages.

\begin{tabular}{|c|c|c|c|c|}
\hline & $\begin{array}{l}\text { A: } \\
\text { Younger } \\
\text { non- } \\
\text { smokers } \\
(n=337)\end{array}$ & $\begin{array}{l}\text { B: } \\
\text { Younger } \\
\text { smokers } \\
(n=313)\end{array}$ & $\begin{array}{l}\text { C: Older } \\
\text { smokers } \\
(n=397)\end{array}$ & $\begin{array}{l}\text { A vs B and/or B vs C group } \\
\text { comparisons }\end{array}$ \\
\hline Gender: \% male & 48.4 & 65.8 & 59.2 & $\begin{array}{l}\text { A vs } B: \chi^{2}(1)=20.1, P<0.001 \\
\text { B vs } C: \chi^{2}(1)=3.2, P=0.07\end{array}$ \\
\hline $\begin{array}{l}\text { Education } \\
\text { Primary/some secondary } \\
\text { Completed secondary } \\
\text { Higher education } \\
\text { qualification }\end{array}$ & $\begin{array}{l}7.4 \\
57.3 \\
33.5\end{array}$ & $\begin{array}{l}11.5 \\
56.5 \\
30.4\end{array}$ & $\begin{array}{l}12.9 \\
57.2 \\
29.0\end{array}$ & $\begin{array}{l}\text { A vs B: } \chi^{2}(2)=3.4, P=0.32 \\
\text { B vs C: } \chi^{2}(2)=0.86, P=0.83\end{array}$ \\
\hline $\begin{array}{l}\text { Smoking status } \\
\text { Daily } \\
\text { Less than daily } \\
\text { Recently quit }\end{array}$ & N/A & $\begin{array}{l}48.6 \\
25.9 \\
25.6\end{array}$ & $\begin{array}{l}74.9 \\
13.9 \\
11.1\end{array}$ & B vs C: $\chi^{2}(3)=52.9, P<0.001$ \\
\hline $\begin{array}{l}\text { Vaping status } \\
\text { Currently using } \\
\text { Past use } \\
\text { Never used }\end{array}$ & $\begin{array}{l}1.8 \\
0 \\
98.2\end{array}$ & $\begin{array}{l}31.3 \\
28.1 \\
40.6\end{array}$ & $\begin{array}{l}21.4 \\
20.7 \\
57.9\end{array}$ & B vs C: $\chi^{2}(2)=21.2, P<0.001$ \\
\hline $\begin{array}{l}\text { Last quit attempt for } \\
\text { current smokers } \\
\text { Within last year } \\
\text { More than a year ago } \\
\text { Never tried } \\
\text { Can't say }\end{array}$ & N/A & $\begin{array}{l}(\mathrm{n}=233) \\
54.5 \\
18.5 \\
18.9 \\
8.2\end{array}$ & $\begin{array}{l}(\mathrm{n}=351) \\
41.3 \\
28.8 \\
14.8 \\
15.1\end{array}$ & B vs C: $\chi^{2}(3)=18.2, P<0.001$ \\
\hline
\end{tabular}

NB: In some comparisons, the 'can't say' responses have not been included so the column percentages may add to less than 100 .

This article is protected by copyright. All rights reserved. 


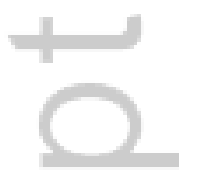

This article is protected by copyright. All rights reserved. 
Table 2. Understanding of general disease and mortality risks of smoking.

\begin{tabular}{|c|c|c|c|}
\hline & $\begin{array}{l}\text { A: Younger } \\
\text { non-smokers } \\
(n=337) \\
\end{array}$ & $\begin{array}{l}\text { B: Younger } \\
\text { smokers } \\
(n=313) \\
\end{array}$ & $\begin{array}{l}\text { C: Older } \\
\text { smokers } \\
(n=397) \\
\end{array}$ \\
\hline \multicolumn{4}{|l|}{ A. Types of harm } \\
\hline Smoking main cause of death: & $85.8 \%$ & $67.7 \%$ & 60.5 \\
\hline AOR (95\% CI) & $\begin{array}{l}2.76(1.87-4.09) \\
P<.001\end{array}$ & Ref & $\begin{array}{l}0.71(0.51-0.97), \\
P=0.03\end{array}$ \\
\hline Smoking major cause of cancer: & 92.6 & 88.9 & 81.9 \\
\hline AOR (95\% CI) & $\begin{array}{l}1.53(0.89-2.65), \\
P=.127\end{array}$ & Ref & $\begin{array}{l}0.55(0.36-0.86), \\
P=0.009\end{array}$ \\
\hline Smoking major cause of heart & 89.0 & 86.3 & 79.9 \\
\hline $\begin{array}{l}\text { disease: } \\
\text { AOR }(95 \% \mathrm{CI})\end{array}$ & $\begin{array}{l}1.24(0.77-1.99), \\
P=.373\end{array}$ & Ref & $\begin{array}{l}0.62(0.41-0.93), \\
P=0.02\end{array}$ \\
\hline Correct for all three harms items & 81.6 & 63.3 & 54.70 \\
\hline AOR (95\% CI) & $\begin{array}{l}2.49(1.73-3.58), \\
P<.001\end{array}$ & Ref & $\begin{array}{l}0.68(0.50-0.93), \\
P=0.015\end{array}$ \\
\hline \multicolumn{4}{|l|}{ Estimated mortality risk } \\
\hline under $40 \%$ & 15.7 & 27.2 & 23.7 \\
\hline 41 to $70 \%$ (accurate) & 24.6 & 22.0 & 26.5 \\
\hline Over $70 \%$ & 37.1 & 18.8 & 16.9 \\
\hline Can’t say & 22.6 & 32.0 & 33.0 \\
\hline AOR: Accurate\# vs Other & $\begin{array}{l}1.16(0.80-1.68) \\
P=.431\end{array}$ & Ref & $\begin{array}{l}1.27(0.90-1.80), \\
P=0.179\end{array}$ \\
\hline \multicolumn{4}{|c|}{ Sources of harm (\% believing > half) } \\
\hline Combustion & $\begin{array}{l}49.9 \% \\
\mathrm{AvB} \chi^{2(1)}=2.16 \\
P=0.17\end{array}$ & $44.1 \%$ & $\begin{array}{l}37.3 \% \\
\mathrm{BvC} \chi^{2(1)}=3.37 \\
P=0.07\end{array}$ \\
\hline Nicotine & $\begin{array}{l}45.7 \% \\
\operatorname{AvB} \chi^{2(1)}= \\
10.54, P<.001\end{array}$ & $33.2 \%$ & $\begin{array}{l}27.2 \% \\
\mathrm{BvC} \chi^{2(1)}=3.03, \\
P=0.08\end{array}$ \\
\hline Tobacco (unburned) & $50.5 \%$ & $42.5 \%$ & $38.8 \%$ \\
\hline
\end{tabular}

This article is protected by copyright. All rights reserved. 


\begin{tabular}{|l|l|l|l|}
\hline & $\begin{array}{l}\mathrm{AvB} \chi^{2}(1)= \\
4.12, P=0.05\end{array}$ & & $\begin{array}{l}\mathrm{BvC} \chi^{2(1)}=0.99, \\
P=0.32\end{array}$ \\
\hline \multirow{2}{*}{ Additives } & $47.2 \%$ & $45.1 \%$ & $39.3 \%$ \\
& $\begin{array}{l}\mathrm{AvB} \chi^{2}=0.29, P \\
=0.59\end{array}$ & & $\begin{array}{l}\mathrm{BvC} \chi^{2}=2.38, \\
P=0.12\end{array}$ \\
\hline
\end{tabular}

AOR, odds ratios adjusted for gender and education; CI, confidence interval.

This article is protected by copyright. All rights reserved. 
Table 3. A novel recategorisation of respondents based on relative concerns about combustion and nicotine.

\begin{tabular}{|l|l|l|l|l|}
\hline Segment* & $\mathrm{N}$ & $\begin{array}{l}\text { Under 25 } \\
\text { smokers } \\
\mathrm{n}=313\end{array}$ & $\begin{array}{l}\text { Over 25 smokers } \\
\mathrm{n}=397\end{array}$ & $\begin{array}{l}\text { All } \\
\mathrm{n}=710\end{array}$ \\
\hline Clearly combustion & 113 & $16.3 \%$ & $15.6 \%$ & $15.9 \%$ \\
\hline Marginally combustion & 89 & $12.5 \%$ & $12.6 \%$ & $12.5 \%$ \\
\hline Nicotine most & 166 & $22.7 \%$ & $23.9 \%$ & $23.4 \%$ \\
\hline Over-concerned & 111 & $17.6 \%$ & $11.9 \%$ & $14.2 \%$ \\
\hline Under-concerned & 111 & $16.9 \%$ & $14.6 \%$ & $15.6 \%$ \\
\hline Disengaged & 130 & $14.1 \%$ & $21.7 \%$ & $18.3 \%$ \\
\hline
\end{tabular}

The six segments are defined in the results section. NB. Differences in distribution between the two smoker sub-samples: Chi-square $=10.51$, $\mathrm{df}=5, P=0.057$

This article is protected by copyright. All rights reserved. 
Table 4. Relationships between relative concern categories and knowledge, related attitudes and current product use and quitting history.

\begin{tabular}{|c|c|c|c|c|c|c|c|}
\hline & $\begin{array}{l}\text { Clearly } \\
\text { combustion } \\
(\mathrm{n}=115) \\
\end{array}$ & $\begin{array}{c}\text { Marginally } \\
\text { combustion } \\
(\mathrm{n}=89)\end{array}$ & $\begin{array}{l}\text { Nicotine most } \\
\qquad(\mathrm{n}=168)\end{array}$ & $\begin{array}{c}\text { Over- } \\
\text { concerned } \\
(n=103)\end{array}$ & $\begin{array}{c}\text { Under- } \\
\text { concerned } \\
(\mathrm{n}=111)\end{array}$ & $\begin{array}{l}\text { Disengaged } \\
(\mathrm{n}=133)\end{array}$ & Comparisons\# \\
\hline $\begin{array}{l}\text { Identifies cancerand heart disease risks and smoking } \\
\text { as main cause of death }\end{array}$ & 64.4 & 60.7 & 67.9 & 86.4 & 51.4 & 24.1 & $\begin{array}{l}\text { A: } \chi^{2}(1)=79.3, P<0.001 \\
\text { B: } \chi^{2}(4)=31.3, P<0.001\end{array}$ \\
\hline \multicolumn{8}{|l|}{ Estimated mortality risk from smoking } \\
\hline$<40 \%$ & 28.7 & 25.8 & 22.0 & 20.4 & 34.2 & 21.1 & A: $\chi^{2}(3)=54.5, P<0.001$ \\
\hline $40 \%$ to $70 \%$ (correct) & 33.0 & 30.3 & 29.8 & 21.3 & 19.8 & 13.5 & $\mathrm{~B} \cdot \gamma^{2}(12)=358 P<0001$ \\
\hline$>70 \%$ & 21.7 & 18.0 & 19.1 & 34.0 & 9.9 & 6.8 & \\
\hline Can’t say & 16.5 & 25.8 & 29.2 & 24.3 & 36.0 & 58.7 & \\
\hline \multicolumn{8}{|l|}{ \% rating as less harmful than reference cigarette: } \\
\hline A, Nicotine gum & 60.9 & 53.9 & 49.4 & 47.6 & 44.1 & 37.5 & $\begin{array}{l}\text { A: } \chi^{2}(1)=7.83, P=0.005 \\
\text { B: } \chi^{2}(4)=7.53, P=0.11\end{array}$ \\
\hline B, Nicotine mouth spray & 53.0 & 47.2 & 41.1 & 33.0 & 41.4 & 30.8 & $\begin{array}{l}\text { A: } \chi^{2}(1)=6.66, P=0.01 \\
\text { B: } \chi^{2}(4)=9.93, P=0.042\end{array}$ \\
\hline C, Vaping device with nicotine e-liquid & 33.9 & 25.8 & 20.8 & 13.6 & 27.9 & 24.8 & $\begin{array}{l}\mathrm{A}: \chi^{2}(1)=.02, P=0.88 \\
\mathrm{~B}: \chi^{2}(4)=14.23, P=0.007\end{array}$ \\
\hline D, Vaping device with nicotine-free e-liquid & 46.1 & 36.0 & 36.3 & 24.3 & 38.7 & 26.3 & $\begin{array}{l}\text { A: } \chi^{2}(1)=5.0, P<0.03 \\
\text { B: } \chi^{2}(4)=11.46, P=0.022\end{array}$ \\
\hline \multicolumn{8}{|l|}{ Importance of information from medical experts } \\
\hline Very/ extremely & 87.8 & 79.8 & 76.2 & 85.4 & 72.1 & 45.9 & $\begin{array}{l}\text { A: } \chi^{2}(2)=64.4, P<0.001 \\
\text { B: } \chi^{2}(4)=12.1, P=0.02\end{array}$ \\
\hline Current product use & & & & & & & $\mathrm{A}: \chi^{2}(1)=8.0, P=0.005$ \\
\hline Current smoker & 75.7 & 82.0 & 81.6 & 68.0 & 90.1 & 90.2 & $\mathrm{~B}: \chi^{2}(4)=17.9, P=0.001$ \\
\hline
\end{tabular}

This article is protected by copyright. All rights reserved. 


\begin{tabular}{|c|c|c|c|c|c|c|c|}
\hline $\begin{array}{l}\text { Current vaper (including dual users) } \\
\text { Not smoking or vaping }\end{array}$ & 22.6 & $\begin{array}{l}29.2 \\
18.0\end{array}$ & $\begin{array}{l}22.6 \\
17.9\end{array}$ & $\begin{array}{l}25.2 \\
27.2\end{array}$ & $\begin{array}{l}42.3 \\
9.9\end{array}$ & $\begin{array}{l}16.5 \\
8.3\end{array}$ & $\begin{array}{l}\text { A: } \chi^{2}(1)=8.2, P=0.004 \\
\text { B: } \chi^{2}(4)=14.7, P=0.005 \\
\text { A: } \chi^{2}(1)=8.3, P=0.004 \\
\text { B: } \chi^{2}(4)=12.2, P=0.016\end{array}$ \\
\hline Past quit attempts for current smokers & $(n=87)$ & $(n=73)$ & $(n=136)$ & $(\mathrm{n}=70)$ & $(n=100)$ & $(n=118)$ & \\
\hline Within last year & 51.7 & 49.3 & 50.7 & 55.7 & 56.0 & 22.9 & $\mathrm{~A}: \chi^{2}(3)=42.7, P<0.001$ \\
\hline More than a year ago & 29.9 & 23.3 & 21.3 & 24.3 & 20.0 & 29.7 & $\mathrm{~B}: \chi^{2}(12)=6.4, P=0.897$ \\
\hline Never tried & 11.5 & 17.8 & 18.4 & 11.4 & 14.0 & 22.0 & \\
\hline Can’t say & 6.9 & 9.6 & 9.6 & 8.6 & 10.0 & 25.4 & \\
\hline
\end{tabular}

\# Comparisons are A= Disengaged vs rest; $\mathrm{B}=$ among the "main five” relative concern categories.' 


\section{REFERENCES}

1. Chapman S, Liberman J. Ensuring smokers are adequately informed: reflections on consumer rights, manufacturer responsibilities, and policy implications. Tob Control 2005;14(Suppl 2):iii8 - ii13.

2. Hoek J. Informed choice and the nanny state: learning from the tobacco industry. Public Health 2015;29:1038-45.

3. Hammond D, Fong GT, McNeill A, Borland R, Cummings KM. Effectiveness of cigarette warning labels in informing smokers about the risks of smoking: Findings from the International Tobacco Control (ITC) Four Country Survey. Tob Control 2006;15(Suppl III):iii19-iii25.

4. Borland R. What do people's estimates of smoking risk mean? Psychol Health 1997;12:513-31.

5. $\quad$ Oakes W, Chapman S, Borland R, Balmford J, Trotter L. "Bulletproof sceptics in life's jungle": which self-excepting beliefs about smoking most predict lack of progression toward quitting. Prev Med 2004;39:776-82.

6. Brewer NT, Morgan JC, Baig SA, Mendel JR, Boynton MH, Pepper JK, et al. Public understanding of cigarette smoke constituents: three US surveys. Tob Control 2017;26:5929.

7. Bernat J, Ferrer, RA, Margolis, KA and Blake KD. US adult tobacco users' absolute harm perceptions of traditional and alternative products, information-seeking behaviors, and (mis)beliefs about chemicals in tobacco products. Addict Behav 2017;71:38-45.

8. Pepper J, Byron, MJ, Ribisl, KM, Brewer, NT. How hearing about harmful chemicals affects smokers' interest in dual use of cigarettes and e-cigarettes. Prev Med 2017;96:144-8. 9. Morgan JC, Byron MJ, Baig SA, Stepanov I, Brewer NT. How people think about chemicals in cigarette smoke: a systematic review. J Behav Med 2017;40:553-464.

10. Moracco KE, Morgan JC, Mendel J, Teal R, Noar SM, Ribisl KM, et al. "My first thought was croutons": Perceptions of cigarettes and cigarette smoke constituents among adult smokers and nonsmokers. Nicotine Tob Res 2016;18:1566-74.

11. Borland R, Cooper J, McNeill A, O'Connor R, Cummings KM. Trends in beliefs about the harmfulness and use of stop-smoking medications and smokeless tobacco products among cigarettes smokers: Findings from the ITC four-country survey. Harm Reduct J 2011;8:21.

12. Czoli C, Fong, GT, Mays,D, Hammond, D. How do consumers perceive differences in risk across nicotine products? A review of relative risk perceptions across smokeless tobacco, e-cigarettes, nicotine replacement therpay and combustible cigarettes. Tob Control 2016;26(e1):e49-e58.

13. Fischoff B. The sciences of science communication. Proc Natl Acad Sci U S A 2013;110(Suppl 3):14033-9.

14. Fischoff B. Risk perception and communication. In: Detels R, Gulliford M, Abdool Karim Q, editors. Oxford Textbook of Global Public Health - Ch 6. UK: Oxford University Press; 2015. 
15. Bruine de Bruin W, Bostrom A. Assessing what to address in science communication. Proc Natl Acad Sci U S A 2013;110(Suppl 3):14062-8.

16. Breakwell GM. The Psychology of Risk. Cambridge: Cambridge University of Press; 2010.

17. Bloom BS, Engelhart MD, Furst EJ, Hill wH, Krathwohl DR. Taxonomy of educational objectives: The classification of eductional goals. Handbook I. New York: David McKay Company; 1956.

18. Fowles J, Dybing E. Application of toxicological risk assessment principles to the chemical contituents of cigarette smoke. Tob Control. 2003;12:424-30.

19. Hoffman L, Hoffmann D. The changing cigarette: chemical studies and bioassays. In: Boyle P, Gray N, Henningfield J, Seffrin J, Zatonski W, editors. Tobacco: Science, Policy and Public Health: Oxford University Press; 2010.

20. Boffetta P, Hecht S, Gray N, Gupta P, Straif K. Smokeless tobacco and cancer. Lancet Oncol 2008;9:667-75.

21. Foulds J, Ramstrom L, Burke M, Fagerstrom K. Effect of smokeless tobacco (snus) on smoking and public health in Sweden. Tob Control 2003;12:349-59.

22. Health Do. Australian cigarette ingredient information. 2018 [25/10/2018]; Available from: http://www.health.gov.au/internet/main/publishing.nsf/Content/health-pubhlth-strategdrugs-tobacco-ingredients.htm.

23. Benowitz NL, Burbank AD. Cardiovascular toxicity of nicotine: Implications for electronic cigarette use. Trends Cardiovasc Med 2016;26:515-23.

24. Benowitz NL. Nicotine addiction. N Engl J Med 2010;362:2295-303.

25. Shiffman S, Ferguson SG, Rohay JM, Gitchell JG. Perceived safety and efficacy of nicotine replacement therapies among US smokers and ex-smokers: relationship with use and compliance. Addiction 2008;103:1371-8.

26. King B, Ndoen E, Borland R. Smokers' risk perceptions and misperceptions of cigarettes, e-cigarettes and nicotine replacement therapies. Drug and Alcohol Review. 2018. 27. Slovic P, Finucane ML, Peters E, MacGregor DG. The affect heuristic. Eur J Oper Res 2007;177:1333-52.

28. Slovic P, Peters E. Risk Perception and Affect. Curr Dir Psychol Sci 2006;15:322-5.

29. Borland R. CEOS Theory: A comprehensive approach to understanding hard to maintain behaviour change. Appl Psychol Health Well Being 2016;9:3-35.

30. Borland R. Understanding Hard to Maintain Behaviour Change: A Dual-Process Approach.: Oxford: Wiley-Blackwell, Addiction Press; 2014.

31. Banks E, Joshy G, Weber MF, Liu B, Grenfell R, Egger S, et al. Tobacco smoking and all-cause mortality in a large Australian cohort study: findings from a mature epidemic with current low smoking prevalence. BMC Med 2015;13:38.

32. Peto R, Lopez AD, Boreham J, Thun M. Mortality from smoking in developed countries, 1950-2010. Oxford: Clinical Trial Service Unit and Epidemiological Studies Unit; 2012.

33. Cameron L, Chan, CKY. Designing health communications: harnessing the power of affect, imagery, and self-regulation. Social and Personality Psychology Compass.

2008;2:262-82.

This article is protected by copyright. All rights reserved. 


\section{University Library}

\section{- M M N E R VA A gateway to Melbourne's research publications}

Minerva Access is the Institutional Repository of The University of Melbourne

Author/s:

King, B;Borland, R;Yong, H-H;Gartner, C;Hammond, D;Lewandowsky, S;O'Connor, R

Title:

Understandings of the component causes of harm from cigarette smoking in Australia

Date:

2019-11-05

Citation:

King, B., Borland, R., Yong, H. -H., Gartner, C., Hammond, D., Lewandowsky, S. \& O'Connor, R. (2019). Understandings of the component causes of harm from cigarette smoking in Australia. DRUG AND ALCOHOL REVIEW, 38 (7), pp.807-817. https://doi.org/10.1111/ dar.12995.

Persistent Link:

http://hdl.handle.net/11343/286578 